\title{
Mechanisms of prolongation of pre-ejection period in patients with left ventricular disease
}

\author{
W. CHEN AND D. GIBSON \\ From the Department of Cardiology, Brompton Hospital, London
}

SUMMARY In order to determine the mechanism underlying prolongation of the pre-ejection period in patients with left ventricular disease, 11 patients with congestive cardiomyopathy and 29 with coronary artery disease, 10 of whom were taking beta-adrenergic blocking drugs, were studied non-invasively. Recordings of carotid pulse, and apex, phon )-, and echocardiogram were obtained. In the absence of treatment with beta-blocking drugs, prolongation of pre-ejection period correlated closely with incoordinate left ventricular wall movement during isovolumic contraction assessed from simultaneous apex and echocardiograms. There was no correlation between pre-ejection period index (PEPI) and end-diastolic dimension and PEPI correlated poorly with fractional shortening and peak Vcf. A PEPI of greater than $140 \mathrm{~ms}$ was associated with incoordinate contraction in all but one case, and of less than $140 \mathrm{~ms}$ with normal contraction in all. Therapeutic doses of beta-blocking drugs caused prolongation of PEPI to a greater extent than would have been predicted from wall movement during isovolumic contraction. Incoordinate left ventricular contraction and a negative inotropic effect both therefore prolong PEPI, but by different mechanisms, whose effects can be separated in individua patients using non-invasive methods based on echocardiography.

Prolongation of pre-ejection period is commonly used to detect the presence of left ventricular disease, though the mechanism of this prolongation of pre-ejection period is obscure. A reduction in 'contractility' is frequently invoked, but this term is not adequately defined, and means little more than the presence of clinical evidence of left ventricular disease. We have, therefore, measured pre-ejection period and other systolic time intervals in patients with ischaemic heart disease or cardiomyopathy, analysing any impairment of left ventricular function at rest in terms of abnormal cavity size, incoordinate contraction, and reduced peak systolic rate of wall movement, measured echocardiographically. These observations were compared with those made during chronic administration of beta-blocking drugs in therapeutic dosage.

\section{Methods}

Systolic time intervals were measured and echocardiographic examinations were performed in 40 patients, who were divided into the following groups:

Group $1: 11$ patients with congestive cardiomyoReceived for publication 15 January 1979 pathy. This diagnosis was made by echocardiography in patients without a history of chest pain or electrocardiographic evidence of infarction, in whom cavity size was increased and the amplitude of wall movement reduced. Since we no longer perform cardiac catheterisation in such patients, this group may have included individuals with advanced ischaemic heart disease. This limitation was accepted, since the pathological process underlying the left ventricular disease was of no importance to the design of the study.

Group 2:19 patients with coronary artery disease, confirmed by coronary arteriography. None of these patients had taken any beta-adrenergic blocking drug within 2 weeks of the study.

Group 3:10 patients with coronary artery disease, again confirmed by coronary arteriography, who were on maintenance treatment with beta-blocking drugs, either propranolol, oxprenolol, or atenolol. In each case, the dose had been adjusted to give maximum therapeutic effect.

Patients with left bundle-branch block, atrial fibrillation, systemic hypertension, or valvar heart disease were excluded from the study. Treatment with digitalis preparations and diuretics was not interrupted. 
SYSTOLIC TIME INTERVALS

Systolic time intervals were derived from simultaneous recordings of phonocardiogram, carotid pulse, and electrocardiogram, made with the patient supine, after a period of approximately 15 minutes rest. The output was displayed on a Cambridge Instruments strip-chart photographic recorder, operating at a paper speed of $100 \mathrm{~mm} / \mathrm{s}$. The electrocardiogram recorded was usually lead II, but occasionally other leads were used when these showed the onset of electrical depolarisation more clearly. Phonocardiograms were recorded from the site where the aortic component of the second sound was heard most easily, using a Cambridge (Leatham) microphone and a highfrequency filter. The pulse tracing was taken from the right carotid artery, using a Cambridge Instruments transducer, with a time constant of $4 \mathrm{~s}$, and a lower frequency limit of $0.05 \mathrm{~Hz}$. The following intervals were measured.

(1) Total electromechanical systole $\left(Q-S_{2}\right)$ : this was measured from the onset of left ventricular depolarisation to the start of the first high-frequency vibration of the aortic component of the second heart sound.

(2) Left ventricular ejection time (LVET): this was measured from the onset of the rapid upstroke of the carotid pulse to the trough of the incisura.

(3) Pre-ejection period (PEP): this was derived by subtracting left ventricular ejection time from Q-S ${ }_{2}$ interval. All intervals were measured to the nearest $5 \mathrm{~ms}$ from 10 successive beats, and average values obtained. Using regression equations derived by Weissler et al. (1969b), the pre-ejection period index (PEPI) was calculated. In addition, values of the ratio PEP/LVET were also derived.

\section{ECHOCARDIOGRAPHIC MEASUREMENTS}

These recordings were made immediately before those made for measurement of the systolic time intervals. Echocardiograms were obtained with either a Cambridge Instruments or a Smith-Kline Ekoline 20 Ultrasonoscope (frequency $2.25 \mathrm{MHz}$, repetition rate $1000 / \mathrm{s}$ ). The output was displayed on a Cambridge Instruments strip chart recorder, at a paper speed of $100 \mathrm{~mm} / \mathrm{s}$. The patients lay 30 degrees on their left side and the transducer was directed to measure the left ventricular dimension, from the left side of the septum to the endocardial surface of the posterior wall at the level of the tips of the mitral valve leaflets. All echocardiograms showed clear, continuous endocardial echoes so that they could be digitised. A simultaneous electrocardiogram and apex cardiogram were also recorded, the latter from the point of maximum impulse, using the same transducer as that used for the carotid pulse.

Echocardiograms and apex cardiograms were digitised as previously described (Venco et al., 1977). Plots were made of the original digitised data, left ventricular dimension and its first derivative with respect to time, normalised rate of change of dimension (VCF) and, finally, the time relations between left ventricular dimension and apex cardiogram, displayed as a loop. At least 3 beats were digitised from each record, and mean values were taken. From these plots, the following measurements were made:

(1) End-diastolic (EDD) and end-systolic (ESD) dimensions.

(2) Fractional shortening, derived as (EDD ESD)/EDD.

(3) Peak rate of reduction of normalised dimension during ejection (peak Vcf).

(4) The change in left ventricular dimension during the time of inscription of the upstroke of the apex cardiogram, between its onset and the ' $E$ ' point (isovolumic contraction), expressed as a percentage of the total dimension change during the cardiac cycle.

\section{STATISTICAL METHODS}

In patients of groups 1 and 2, PEPI was correlated with EDD, fractional shortening, peak Vcf, and percentage reduction in left ventricular dimension during isovolumic contraction. Multiple regression analysis was also performed to assess the relative associations between PEP or PEP/LVET and EDD, fractional shortening, peak Vcf, and dimension change during the upstroke of the apex cardiogram.

\section{Results}

The systolic time intervals and echocardiographic measurements in the 3 groups of patients are given in detail in Table 1.

In groups 1 and 2, PEPI was found to correlate most strongly with left ventricular dimension change during the upstroke of the apex cardiogram $(r=0.76, \quad P<0.001)$. There was no significant correlation with end-diastolic dimension $(r=0 \cdot 22$, NS) and correlation was poor with fractional shortening $(r=0.39, P<0.5)$ and peak $\operatorname{Vcf}(r=0.42$, $P<0.05)$. The relation between PEPI and dimension change during the upstroke of the apex cardiogram is shown in Fig. 1 . Of 10 patients with PEPI less than $140 \mathrm{~ms}$, all had a left ventricular dimension change less than 15 per cent, the upper limit of normal (Venco et al., 1977), while 19 of the remaining 20 had a left ventricular dimension change greater than 15 per cent. This relation is 
very significant statistically (Fisher's exact probability test, $\mathrm{P}<0.0001$ ).

The PEP/LVET ratio in groups 1 and 2 also correlated best with left ventricular dimension change during the upstroke of the apex cardiogram $(\mathbf{r}=0.77, \mathrm{P}<0.001)$, but also, to a lesser extent, with fractional shortening $(\mathrm{r}=-0.53, \mathrm{P}<0.002)$ and peak $\operatorname{Vcf}(r=-0.49, \mathrm{P}<0.01)$. There was no significant correlation with end-diastolic dimension. Multiple correlation on PEP/LVET, peak Vcf, and left ventricular dimension change resulted in the following regression equation:

$\mathrm{PEP} / \mathrm{LVET}=0.35-0.038$ peak $\mathrm{Vcf}+0.0084$

(dimension change).

Table 1 Systolic time intervals and echocardiographic measurements in patients with congestive cardiomyopathy and coronary artery disease

\begin{tabular}{|c|c|c|c|c|c|c|}
\hline \multirow{2}{*}{$\begin{array}{l}\text { Case } \\
\text { no. }\end{array}$} & \multirow[b]{2}{*}{$\begin{array}{c}\text { PEPI } \\
(m s)\end{array}$} & \multirow{2}{*}{$\begin{array}{l}P E P / \\
L V E T\end{array}$} & \multirow{2}{*}{$\begin{array}{r}E D D \\
(\mathrm{~cm})\end{array}$} & \multirow{2}{*}{$\frac{E D D-E S D}{E D D}$} & \multirow{2}{*}{$\begin{array}{l}\text { Peak } \\
V c f \\
\left(s^{-1}\right)\end{array}$} & \multirow{2}{*}{$\begin{array}{l}\text { DMUP } \\
(\%)\end{array}$} \\
\hline & & & & & & \\
\hline \multicolumn{7}{|c|}{ Group 1 Congestive cardiomyopathy } \\
\hline 1 & 117 & 0.29 & $7 \cdot 2$ & $0 \cdot 11$ & 0.65 & 15 \\
\hline 2 & 164 & 0.58 & $6 \cdot 2$ & 0.14 & 0.82 & 21 \\
\hline 3 & 157 & 0.59 & $6 \cdot 5$ & $0 \cdot 10$ & 0.80 & 25 \\
\hline 4 & 164 & 0.57 & $6 \cdot 2$ & 0.095 & $1 \cdot 4$ & 28 \\
\hline 5 & 162 & 0.56 & 6.9 & $0 \cdot 12$ & 0.85 & 30 \\
\hline 6 & 143 & 0.45 & $5 \cdot 7$ & 0.35 & $2 \cdot 2$ & 25 \\
\hline 7 & 155 & 0.65 & $6 \cdot 3$ & 0.16 & $1 \cdot 4$ & 28 \\
\hline 8 & 171 & 0.67 & $5 \cdot 7$ & 0.16 & $1 \cdot 1$ & 29 \\
\hline 9 & 153 & 0.61 & $6 \cdot 8$ & 0.15 & $1 \cdot 1$ & 36 \\
\hline 10 & 124 & 0.37 & $8 \cdot 2$ & 0.15 & $1 \cdot 3$ & 5 \\
\hline 11 & 141 & 0.54 & $6 \cdot 2$ & 0.12 & 1.0 & 28 \\
\hline 12 & 155 & 0.52 & $8 \cdot 2$ & 0.24 & 1.5 & 28 \\
\hline
\end{tabular}

Group 2: Coronary artery disease not on beta-blocker

\begin{tabular}{|c|c|c|c|c|c|c|}
\hline & & & & & & \\
\hline 13 & 115 & 0.33 & $6 \cdot 3$ & 0.20 & 1.5 & 10 \\
\hline 14 & 124 & 0.42 & $3 \cdot 7$ & 0.14 & $2 \cdot 0$ & 14 \\
\hline 15 & 129 & 0.32 & $4 \cdot 3$ & 0.44 & $2 \cdot 8$ & 12 \\
\hline 16 & 151 & 0.60 & $4 \cdot 0$ & 0.11 & $1 \cdot 1$ & 34 \\
\hline 17 & 168 & 0.71 & $5 \cdot 4$ & 0.22 & $1 \cdot 7$ & 19 \\
\hline 18 & 116 & 0.29 & $4 \cdot 7$ & 0.39 & 2.5 & 10 \\
\hline 19 & 168 & 0.51 & $5 \cdot 7$ & 0.28 & 1.6 & 27 \\
\hline 20 & 167 & 0.58 & 6.8 & 0.17 & $1 \cdot 2$ & 34 \\
\hline 21 & 155 & 0.57 & $5 \cdot 2$ & 0.33 & 2.5 & 37 \\
\hline 22 & 138 & 0.43 & 4.9 & 0.20 & 1.9 & 14 \\
\hline 23 & 154 & 0.46 & $4 \cdot 8$ & 0.21 & $1 \cdot 2$ & 28 \\
\hline 24 & 147 & 0.47 & $5 \cdot 8$ & 0.17 & 1.5 & 21 \\
\hline 25 & 145 & 0.39 & 3.9 & 0.18 & 1.4 & 12 \\
\hline 26 & 95 & 0.22 & $4 \cdot 7$ & 0.34 & $2 \cdot 4$ & 7 \\
\hline 27 & 128 & $0 . \overline{33}$ & $4 \cdot 0$ & 0.36 & $2 \cdot 4$ & 9 \\
\hline 28 & 165 & 0.51 & $4 \cdot 5$ & 0.22 & 1.9 & 37 \\
\hline 29 & 149 & 0.53 & $7 \cdot 5$ & 0.080 & 0.45 & 40 \\
\hline 30 & 128 & 0.34 & $4 \cdot 2$ & 0.40 & $2 \cdot 3$ & 8 \\
\hline Gro & $3 \mathrm{Co}$ & ry art & disea & beta-b & & \\
\hline 31 & 147 & 0.44 & $4 \cdot 8$ & $0 \cdot 17$ & $1 \cdot 3$ & 34 \\
\hline 32 & 146 & 0.43 & $5 \cdot 5$ & 0.18 & 0.80 & 15 \\
\hline 33 & 198 & 0.69 & 6.5 & $0 \cdot 10$ & 0.90 & 31 \\
\hline 34 & 169 & 0.53 & $5 \cdot 4$ & 0.18 & $1 \cdot 3$ & 11 \\
\hline 35 & 147 & 0.42 & $4 \cdot 7$ & 0.23 & 1.9 & 3 \\
\hline 36 & 154 & 0.48 & $4 \cdot 5$ & 0.084 & 1.0 & 22 \\
\hline 37 & 133 & 0.35 & $5 \cdot 4$ & 0.34 & $2 \cdot 3$ & 10 \\
\hline 38 & 129 & 0.36 & $5 \cdot 8$ & 0.39 & $2 \cdot 0$ & 11 \\
\hline 39 & 167 & 0.50 & 6.0 & 0.22 & 1.4 & 23 \\
\hline 40 & 148 & 0.39 & $5 \cdot 1$ & 0.39 & $1 \cdot 4$ & 15 \\
\hline
\end{tabular}

PEPI, pre-ejection period index; LVET, left ventricular ejection time; EDD, end-diastolic dimension; ESD, end-systolic dimension; Vcf, velocity of circumferential fibre shortening; DMUP, dimension change during upstroke of apex cardiogram.
The multiple correlation coefficient was 0.79 . In addition, peak Vcf and fractional shortening were themselves significantly correlated $(r=0.90)$, and so could not be treated as independent variables.

In group 3 patients, who were taking therapeutic doses of beta-blocking drugs, values of PEPI were greater than would have been predicted from dimension change during isovolumic contraction in 9 out of 10 patients (Fig. 2).

\section{Discussion}

There is much evidence to suggest that the preejection period is prolonged by the presence of left ventricular disease. This has been reviewed in detail by Harris (1974), and shown to be true not only for primary myocardial disease (Spodick et al., 1972; Armstrong et al., 1973), but also for the myocardial disease occurring in hypertension (Tarazi et al., 1969), valvar heart disease, or coronary artery disease (Jezek, 1963; Pouget et al., 1971; Meng et al., 1976). However, analysis of the underlying disturbance has been limited by difficulties in the definition of myocardial contractility. This has been defined in terms of the findings of experiments on isolated heart muscle, whose theoretical basis now appears dubious, and

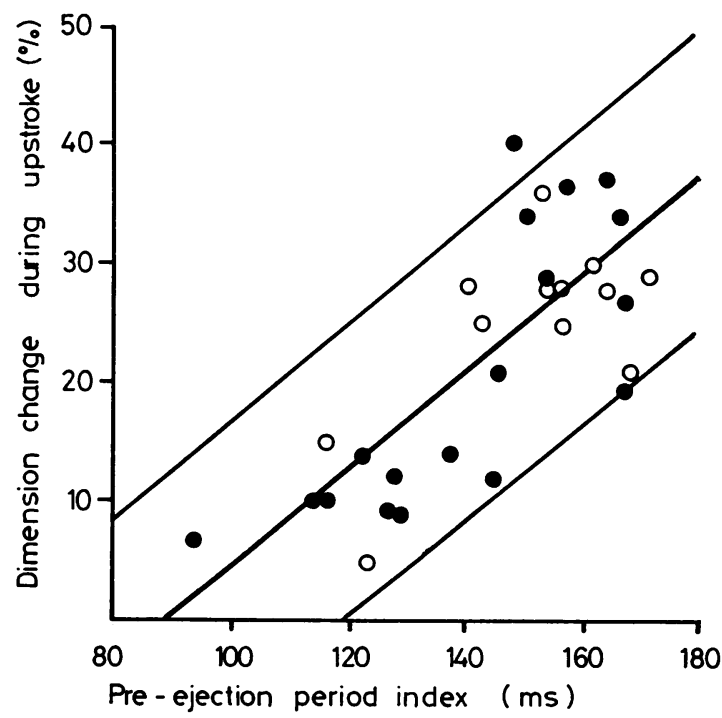

Fig. 1 Relation between prolongation of pre-ejection period and abnormal left ventricular dimension change during upstroke of apex cardiogram in patients with coronary artery disease $(O)$ or congestive cardiomyopathy (O). 
whose extrapolation to patients with cardiac disease unsatisfactory. In the present study, therefore, we have avoided these ideas, and instead attempted to describe clinical left ventricular disease in terms of (1) abnormal cavity size, (2) reduced rates of left ventricular wall movement, and (3) contraction pattern. These variables can readily be measured by non-invasive techniques based on echocardiography which have been validated in our laboratory against invasive methods. Estimates of transverse left ventricular diameter at the level of the mitral valve can be made by echocardiography, and agree with those derived from angiocardiograms (Gibson, 1973). At end-diastole, these are little affected by an incoordinate left ventricular contraction pattern (Ludbrook et al., 1973). Measurement of peak Vcf has also been validated against angiocardiography, and in patients with a co-ordinate contraction pattern and competent mitral valve it has been shown to correlate closely with peak left ventricular $\mathrm{dP} / \mathrm{dt}$ (Gibson and Brown, 1975a, 1976). Finally, abnormal changes in left ventricular dimension during the time of inscription of the upstroke of the apex cardiogram between the onset and the ' $E$ ' point correlate closely with regional disturbances of wall movement during early systole, shown angiographically (Doran et al., 1978), independent of other abnormalities of left ventricular wall movement that may be present.

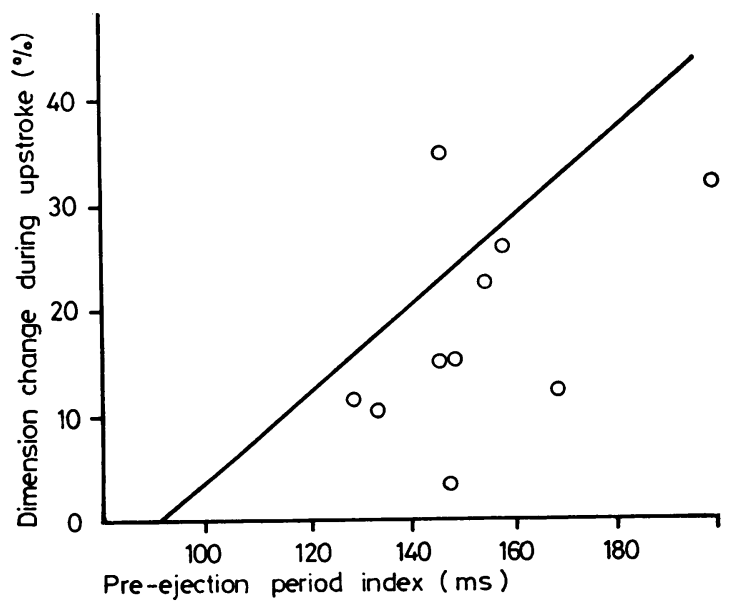

Fig. 2 Effect of therapeutic doses of beta-adrenergic blocking drugs on relation between pre-ejection period and abnormal dimension changes during isovolumic contraction. The regression line is derived from data of Fig. 1.
The present results show clearly that prolongation of pre-ejection period is associated with abnormal dimension changes during the upstroke of the apex cardiogram, but not with either an increased transverse cavity dimension or a reduced peak Vcf. It might be objected that some of these measurements of cavity size or peak Vcf were obtained in patients with incoordinate wall movement and are, therefore, not representative of the behaviour of the left ventricle as a whole. However, they are clearly abnormal, whether or not they are representative, and so should have been associated with values of PEPI outside the normal range, if they were indeed the basis of the prolongation of preejection period seen in patients with heart disease. Secondly, when the subgroup of patients was considered in whom apex cardiogram dimension relations were normal and thus in whom contraction patterns would be expected to be more uniform, the same lack of correlation was found. Thus normal values of PEPI were seen in association with cavity dimensions of up to $8.2 \mathrm{~cm}$, fractional shortening as low as $0 \cdot 15$, or a peak Vcf of $0.65 \mathrm{~s}^{-1}$.

A second limitation of the study is that dimension changes during the upstroke of the apex cardiogram have been shown to be sensitive and specific in detecting, but not necessarily in quantifying, the degree of incoordinate contraction judged angiographically. It is probably more appropriate, therefore, to use this method simply to categorise early systolic wall movement in individual patients as either normal or abnormal. When groups 1 and 2 patients were divided in this way, there was virtually no overlap between the two (Table 2). Nevertheless, the relation between the percentage dimension change during isovolumic contraction and prolongation of PEPI (Fig. 1) suggests that these measurements may, in fact, be regarded as semiquantitative. We therefore conclude that prolongation of pre-ejection period in untreated patients with coronary artery disease or cardiomyopathy is the

Table 2 Relation between PEPI and reduction in $L V$ dimension during period of inscription of upstroke of apex cardiogram and coronary artery disease not receiving $\beta$-blockers.

\begin{tabular}{lll}
\hline & $\begin{array}{l}\text { Reduction in LV dimension } \\
\text { during period of inscription } \\
\text { of upstroke of apex } \\
\text { cardiogram }<15 \%\end{array}$ & $\begin{array}{l}\text { Reduction in LV dimension } \\
\text { during period of inscription } \\
\text { of upstroke of apex } \\
\text { cardiogram }>15 \%\end{array}$ \\
\hline PEPI \\
$<140 \mathrm{~ms}$ & 10 & 0 \\
PEPI & 1 & 19 \\
$>140 \mathrm{~ms}$ & 1 &
\end{tabular}

Fisher exact probability test, $P<0.0001$ 
result of asynchronous onset of contraction rather than slow contraction or abnormal cavity size.

The oscurrence of abnormal wall movement early in systole has been recognised in patients with coronary artery disease for some years, and was described in detail by Karliner et al. (1971) and, more recently, by Gibson et al. (1978), using techniques for displaying regional left ventricular wall movement so that such abnormalities of timing could be easily appreciated. Left ventricular contraction patterns in patients with congestive cardiomyopathy were described by Kreulen et al. (1973), who noted that in approximately 50 per cent there was angiocardiographic evidence of incoordinate movement. In all these patients, the method of angiographic analysis is of importance. Although the most obvious abnormalities seen on direct inspection of the cine film are those of regional amplitude of wall movement, these areas do not necessarily show disturbed movement in early systole. Conversely, regions behaving abnormally in early systole frequently undergo a normal amplitude of movement later in ejection, though their timing may be delayed compared to the remainder of the ventricle (Gibson et al., 1978). It has previously been shown that abnormal dimension changes during the upstroke of the apex cardiogram correlate specifically with those shown angiographically to occur in early systole, and are unrelated to regional reduction in amplitude (Doran et al., 1978). Prolongation of pre-ejection period in our patients, therefore, is also likely to have been related specifically to these early systolic regional abnormalities of wall movement. This correlation would not have been detected unless the methods used had been based on a technique of angiographic analysis capable of distinguishing these disturbances of timing from the more commonly recognised ones of amplitude.

If activation is normal, then pre-ejection period depends on end-diastolic aortic and left ventricular pressures and the rate of rise of the left ventricular pressure pulse. Since hypertensive patients were not studied, and since left atrial pressure is likely to have been high rather than low in the presence of left ventricular disease, prolonged pre-ejection period in our patients was the result of reduced rate of left ventricular pressure rise. Such a reduction in peak left ventricular $\mathrm{dP} / \mathrm{dt}$ has been shown in dogs by Rushmer (1956) by inducing incoordinate contraction using ventricular pacing. These observations were confirmed in man by Gibson and Brown (1975b), who showed that reduction in peak $\mathrm{dP} / \mathrm{dt}$ correlated with the distortion of the left ventricular pressure dimension loop. The present results are compatible with these findings, and suggest that incoordinate left ventricular contaction during early systole causes the appearance of disturbed time relations between changes in dimension and the apex cardiogram, and also prolongs pre-ejection period by reducing the rate of rise of left ventricular pressure, thus explaining the statistical association between the two.

Pre-ejection period is also prolonged by propranolol in normal subjects and patients with heart disease (Harris et al., 1967; Hunt et al., 1970). This finding was confirmed in the present study, where it was also apparent that it was not associated with the expected degree of dimension change early in systole, suggesting that the mechanism by which it was brought about was different from that associated with heart disease. Though there is some evidence that propranolol administration may aggravate abnormalities of wall movement in patients with ischaemic heart disease (Helfant et al., 1971), other studies have shown either no change (Shubrooks et al., 1975) or an improvement (Coltart et al., 1975). It, therefore, seems reasonable to suppose that prolongation of pre-ejection period by propranolol reflects a reduction in contraction velocity due simply to its activity as a beta-adrenoceptor blocking drug. The methods we have used are capable of distinguishing between slow contraction and incoordinate contraction, not only when they occur separately, but also when they occur together in the same patient. In contrast, both mechanisms cause pre-ejection period to be prolonged, and so cannot be distinguished using this latter method alone. It cannot be suggested, therefore, that left ventricular disease and drugs with a negative inotropic effect have the same action on the myocardium merely because they both prolong the pre-ejection period.

Abnormalities of left ventricular function have also been related to the ratio PEP/LVET. This was shown, in a large group of patients with heart disease of different types, to correlate with ejection fraction (Garrard et al., 1970). However, when patients with coronary artery disease alone were considered, there was no such correlation. This lack of correlation has since been confirmed by other workers (Parker and Just, 1974), though we were unable to confirm or deny this relation in the present study. Nevertheless, the demonstration of greatly increased cavity size, reduced amplitude of wall movement, and normal PEPI and PEP/LVET in patients with this diagnosis, makes it unlikely to have applied in our patients. Stack et al. (1976) has also described an even closer correlation between fractional shortening and PEP/LVET in patients with primary myocardial disease or coronary artery disease, which was not confirmed in the present 
study, the weak correlation demonstrated being of no clinical value in individual patients. It does seem, however, that the addition of ejection time in the ratio PEP/LVET increases the correlation with more widely measured variables such as Vcf or fractional shortening, compared with PEPI, at the expense of reducing its specificity as an index of incoordinate contraction.

The present results allow interpretations of previous observations on systolic time intervals to be extended. Pre-ejection period is prolonged in a proportion of patients with chronic ischaemic heart disease, particularly in those who develop left ventricular aneurysm (Jezek, 1963) or 'heart failure' (Weissler et al., 1969a). Prolongation, to a lesser extent, may also occur in patients with angina pectoris even in the absence of other manifestations of left ventricular disease (Pouget et al., 1971). These observations are all compatible with the incidence and associations of abnormal early systolic wall movement shown by angiography (Gibson et al., 1978). After aortic valve replacement, increased PEP is explicable by an early period of incoordinate contraction caused by the operation itself (Seabra-Gomes et al., 1976), comparable to that shown by echocardiography after aortic valve replacement by Venco et al. (1976). Alternatively, a reduction in PEP may occur, probably because of increased sympathetic activity, as shown by Matlof et al. (1973) after aortocoronary saphenous vein bypass grafting. Failure of PEP to shorten subsequently has been associated with the presence of either left ventricular disease or graft occlusion (Johnson et al., 1972). Observations on changes in PEP after acute myocardial infarction are also in line with the present results, and are explicable on the basis of the separate effects of ventricular disease and adrenergic stimulation. By contrast, the echocardiographic methods that we have used may have value in studying such patients by virtue of their ability to separate these two effects and to detect incoordinate contraction even in the presence of increased sympathetic activity.

Study of left ventricular function by means of systolic time intervals has always been associated with persistent ambiguity. On the one hand, there is evidence to suggest that their measurement detects a clinically significant aspect of left ventricular function, while on the other hand they do not correlate closely with any of the routine haemodynamic or angiographic measurements usually made in patients with left ventricular disease. This discrepancy has led to doubt as to their value in the clinical assessment of patients with coronary artery disease (Parker and Just, 1974), since they fail to correlate with ejection fraction, 'contractility indices', or asynergy determined from inspection of ventriculograms. Demonstration of specific correlation with abnormal early systolic wall movement clarifies the genesis of prolongation of the preejection period and thus will help with the interpretation of abnormalities of the systolic time intervals observed in patients with left ventricular disease. It may also be possible to use the large amount of published information based on measurement of the systolic time intervals to extend appreciation of the physiological significance of the normal synchronous left ventricular wall movement and to assess the clinical and epidemiological consequences of incoordinate contraction.

\section{References}

Armstrong, T. G., Lewis, B. S., and Gotsman, M. S. (1973). Systolic time intervals in constrictive pericarditis and severe myocardial disease. American Heart fournal, 85, 6-12.

Coltart, D. J., Alderman, E. L., Robison, S. C., and Harrison, D. C. (1975). Effect of propranolol on left ventricular function, segmental wall motion and diastolic pressurevolume relation in man. British Heart fournal, 37, 357-364.

Doran, J. H., Traill, T. A., Brown, D. J., and Gibson, D. G. (1978). Detection of abnormal left ventricular wall movement during isovolumic contraction and early relaxation: comparison of echo- and angiocardiography. British Heart fournal, 40, 367-371.

Garrard, C. L., jun, Weissler, A. M., and Dodge, H. T. (1970). The relationship of alterations in systolic time intervals to ejection fraction in patients with cardiac disease. Circulation, 42, 455-462.

Gibson, D. G. (1973). Estimation of left ventricular size by echocardiography. British Heart fournal, 35, 128-134.

Gibson, D. G., and Brown, D. J. (1975a). Measurement of peak rates of left ventricular wall movement in man. Comparison of echocardiography with angiography. British Heart fournal, 37, 677-683.

Gibson, D. G., and Brown, D. J. (1975b). Assessment of disordered left ventricular contraction from simultaneous measurements of left ventricular pressure and dimension. In Performance Ventriculaire Gauche Chez l'Homme, pp. 239-248, ed P. Besse and H. Bricaud. Expansion Scientifique Francaise, Paris.

Gibson, D. G., and Brown, D. J. (1976). Assessment of left ventricular systolic function in man from simultaneous echocardiographic and pressure measurements. British Heart fournal, 38, 8-17.

Gibson, D. G., Doran, J. H., Traill, T. A., and Brown, D. J. (1978). Abnormal left ventricular wall movement during early systole in patients with angina pectoris. British Heart fournal, 40, 758-766.

Harris, W. S. (1974). Systolic time intervals in the noninvasive assessment of left ventricular performance in man. In Cardiac Mechanics, pp. 233-292, ed I. Mirsky, D. N. Ghista, and H. Sandler. John Wiley, New York.

Harris, W. S., Schoenfeld, C. D., and Weissler, A. M. (1967). Effects of adrenergic activation on the systolic pre-ejection period, heart rate and arterial pressure in man. Fournal of Clinical Investigation, 46, 1704-1714.

Helfant, R. H., Herman, M. V., and Gorlin, R. (1971). Abnormalities of left ventricular contraction induced by beta blockade. Circulation, 43, 641-647.

Hunt, D., Sloman, G., Clark, R. M., and Hoffman, G. (1970). Effects of beta adrenergic blockade on the systolic time 
intervals. American fournal of the Medical Sciences, 259, 97-113.

Jezek, V. (1963). Clinical value of the polygraphic tracing in the study of the sequence of events during cardiac contraction. Cardiologia, 43, 298-316.

Johnson, A. D., O'Rourke, R. A., Karliner, J. S., and Burian, C. (1972). Effect of myocardial revascularization on systolic time intervals in patients with left ventricular dysfunction. Circulation, 45 and 46, Suppl. I, 91-96.

Karliner, J. S., Bouchard, P. J., and Gault, J. H. (1971). Dimensional changes of the human left ventricle prior to aortic valve opening. Circulation, 44, 312-322.

Kreulen, T. H., Gorlin, R., and Herman, M. V. (1973). Ventriculographic patterns and hemodynamics in primary myocardial disease. Circulation, 47, 299-308.

Ludbrook, P., Karliner, J. S., Peterson, K., Leopold, G., and O'Rourke, R. A. (1973). Comparison of ultrasound and cineangiographic measurements of left ventricular performance in patients with and without wall motion abnormalities. British Heart fournal, 35, 1026-1032.

Matlof, H., Hultgren, H. N., Pfeifer, J. F., and Harrison, D. C. (1973). Cardiac function assessed by systolic time intervals after aortocoronary saphenous vein bypass surgery. British Heart fournal, 35, 714-719.

Meng, R., Hollander, C., Liebson, P. R., Teran, J. C., Barresi, V., and Laurie, M. (1976). The use of noninvasive methods in the evaluation of left ventricular performance. I Relation of systolic time intervals to angiographic assessment of coronary artery disease. American Heart Fournal, 90, 134-144.

Parker, M. E., and Just, H. G. (1974). Systolic time intervals in coronary artery disease: fact or fancy? British Heart fournal, 36, 368-376.

Pouget, J. M., Harris, W. S., Mayron, B. R., and Naughton, J. P. (1971). Abnormal response of systolic time intervals in patients with angina pectoris. Circulation, 43, 289-298.

Rushmer, R. F. (1956). Initial phase of ventricular systole: asynchronous contraction. American fournal of Physiology, 184, 188-194.
Seabra-Gomes, R., Sutton, R., and Parker, D. J. (1976). Left ventricular function after aortic valve replacement. British Fournal, 38, 491-496.

Shubrooks, S. J., jun, Zir, C. M., Dinsmore, R. E., and Harthorne, J. W. (1975). Left ventricular wall motion response to intravenous propranolol. Circulation, 52, 124129.

Spodick, D. H., Pigott, V. M., and Chirife, R. (1972). Preclinical cardiac malfunction in chronic alcoholism. Comparison with matched normal controls and with alcoholic cardiomyopathy. New England fournal of Medicine, 287, 677-680.

Stack, R. S., Lee, C. C., Reddy, S. P., Taylor, M. L., and Weissler, A. M. (1976). Left ventricular performance in coronary artery disease evaluated with systolic time intervals and echocardiography. American fournal of Medicine, 37, 331-339.

Tarazi, R. C., Frohlich, E. D., and Dustan, H. P. (1969). Left atrial abnormality and ventricular pre-ejection period in hypertension. Diseases of the Chest, 55, 214-218.

Venco, A., Gibson, D. G., and Brown, D. J. (1977). Relation between apexcardiogram and changes in left ventricular pressure and dimension. British Heart fournal, 39, 117-125.

Venco, A., Sutton, M. G., St. J., Gibson, D. G., and Brown, D. J. (1976). Non-invasive assessment of left ventricular function after correction of severe aortic regurgitation. British Heart fournal, 38, 1324-1331.

Weissler, A. M., Harris, W. S., and Schoenfeld, C. D. (1969a). Systolic time intervals in heart failure in man. Circulation, 37, 149-159.

Weissler, A. M., Harris, W. S., and Schoenfeld, C. D. (1969b). Bedside technics for the evaluation of ventricular function in man. American fournal of Cardiology, 23, 577583.

Requests for reprints to Dr D. Gibson, Cardiac Department, Brompton Hospital, Fulham Road, London SW3 6HP. 